\title{
СИНТЕЗ И ИЗУЧЕНИЕ МЕДЬСОДЕРЖАЩИХ ПОЛИМЕРОВ НА ОСНОВЕ СУЛЬФАТОВ МИКРОКРИСТАЛЛИЧЕСКОЙ ЦЕЛЛЮЛОЗЫ
} ИЗ ДРЕВЕСИНЫ ЛИСТВЕННИЦЫ

(C) А.В. Левданский ${ }^{1}$, Н.Ю. Васильева ${ }^{1,2}$, Н.Г. Максимов ${ }^{1}$, А.А. Карачаров ${ }^{1}$, В.А. Левданский ${ }^{1}$, Г.П. Скворцова ${ }^{1}$, Б.Н. Кузнецов ${ }^{1,2^{*}}$, L. Djakovitch ${ }^{3}$, C. Pinel $^{3}$

${ }^{1}$ Институт химии и химической технологии СО РАН, ФИЦ КНЦ СО РАН, Академгородок, 50-24, Красноярск, 660036 (Россия), e-mail: inm@icct.ru

${ }^{2}$ Сибирский федеральный университет, пр. Свободный, 79, Красноярск, 660041 (Россия)

${ }^{3}$ IRCELYON, 2 avenue Albert Einstein, F-69626 Villeurbanne Cedex, Lyon (France)

Впервые методом ионного обмена осуществлен синтез водорастворимых медьсодержащих полимеров на основе сульфатов микрокристаллической целлюлозы (Cu-СМКЦ). Состав полученных продуктов изучен с помощью химического метода и рентгеноспектрального микроанализа. Содержание меди в полученных образцах Сu-СМКЦ составило 12,6-14,1\%. Отсутствие натрия в полученном полимере свидетельствует о полном замещении катионов натрия в натриевой соли сульфата МКЦ на катионы меди. Строение медьсодержащего сульфата микрокристаллической целлюлозы изучено методами рентгенофазового анализа (РФА), инфракрасной спектроскопии (ИКС) и электронного парамагнитного резонанса (ЭПР). Показано, что Сu-СМКЦ и натриевая соль сульфата МКЦ имеют аморфное строение в отличие от образцов исходной МКЦ, которые обладают высокой степенью кристалличности. Установлено, что образцы $\mathrm{Cu}-\mathrm{CMKЦ} \mathrm{представляют} \mathrm{собой} \mathrm{медьсодержащую} \mathrm{солевую} \mathrm{систему,} \mathrm{имеющую} \mathrm{псевдокристаллическое} \mathrm{строение.}$ Методом атомно-силовой микроскопии (АСМ) показано, что поверхность пленки Сu-СМКЦ состоит из однородных частиц, имеющих сферическую или слегка вытянутую форму и размеры порядка 70 нм. По своему фазовому составу поверхность пленки достаточно однородна и не содержит посторонних примесей.

Ключевые слова: сульфат целлюлозы, ионный обмен, медьсодержащие полимеры, микрокристаллическая целлюлоза, состав, строение.

Работа выполнена при финансовой поддержке РФФИ и Правительства Красноярского края в рамках научного проекта № 16-43-242083, а также в рамках российско-франиузского МНО «Каталитическая переработка биомассы в иченные продукты». В работе использованы приборы Красноярского регионального центра коллективного пользования СО РАН.

Левданский Александр Владимирович - научный сотрудник, кандидат химических наук, тел. (391) 205-19-42, e-mail: alexsander.1@mail.ru Васильева Наталья Юрьевна - старший научный сотрудник, кандидат химических наук, доцент, тел. (391) 205-19-42, e-mail: vasilyeva.nata@mail.ru Максимов Николай Геннадьевич - ведущий научный сотрудник, кандидат химических наук, тел. (391) 205-19-42, e-mail: inm@icct.ru Карачаров Антон Александрович - научный сотрудник, кандидат химических наук, тел. (391) 205-19-28, e-mail: antonkaracharov@ya.ru

Продолжение нас. 56

\section{Введение}

Полисахариды растительного происхождения используются в качестве полимерных носителей для адресной доставки лекарственных веществ [1]. Широкое применение нашли декстраны [2], производные крахмала [3] и целлюлозы [4].

Полисахариды также широко используют для получения новых металлсодержащих полимеров с уникальными свойствами [5]. Особый практический интерес представляют полимерные материалы, содержащие такие металлы, как серебро,

\footnotetext{
* Автор, с которым следует вести переписку.
} 
медь, железо, кобальт и никель. Эти металлы обладают бактерицидными, антимикробными и противогрибковыми свойствами и играют важную роль в регуляции многих функций человеческого организма [6-8].

Для получения антибактериальных нановолокон, содержащих на своей поверхности наночастицы серебра $\mathrm{Ag}^{+}$, авторы работы [7] использовали волокна ацетата целлюлозы (АЦ). Было показано, что нановолокна АЦ, содержащие наночастицы серебра со средними размерами 21 нм, проявили высокую противомикробную активность.

В работе [8] описаны получение и свойства нанокомпозитов на основе биоразлагаемого полимера карбоксиметилцеллюлозы (КМЦ) и катионов металлов (меди, серебра, индия, железа). Их синтез осуществляли путем взаимодействия соответствующих солей металлов с натриевыми солями КМЦ в водной среде при комнатной температуре. Полученные нанокомпозиты могут найти применение в создании антибактериальных и противогрибковых покрытий, пищевых упаковочных материалов и биомедицинских устройств.

Перспективным является использование водорастворимых сульфатов целлюлозы в качестве полисахаридной матрицы при получении металлсодержащих полимеров [5].

Цель данной работы - разработка нового способа синтеза водорастворимых медьсодержащих полимеров сульфатов микрокристаллической целлюлозы (Сu-СМКЦ), основанного на ионном обмене, и изучение их строения физико-химическими методами.

\section{Экспериментальная часть}

В качестве исходного сырья использовали микрокристаллическую целлюлозу (МКЦ), полученную из древесины лиственницы сибирской (Larix sibirica Ledeb.) по методике, описанной в [9]. Степень полимеризации (СП), рассчитанная по вязкости растворов МКЦ в ЖВНК на вискозиметре типа ВПЖ-3 [10], составляла 134. Степень кристалличности (СК) МКЦ, определенная по отношению интенсивностей рефлекса при углах 22 и $19^{\circ}$ методом Сегала [11], составляла 0,66.

Получение сульфатов МКЦ осуществляли по методике [12] сульфатированием МКЦ хлорсульфоновой кислотой в диоксане с последующим выделением сульфата МКЦ в виде натриевой соли.

Получение медьсодержащих полимеров сульфатов МКЦ. Медьсодержащие полимеры сульфатов МКЦ (Сu-СМКЦ) получали из натриевой соли сульфата МКЦ методом ионного обмена с использованием ионообменной смолы КУ-2-8 в $\mathrm{Cu}^{+}-$-орме по стандартной методике [13]. Предварительно ионообменную смолу КУ-2-8, вырабатываемую в промышленности в $\mathrm{Na}^{+}$-форме, переводили в $\mathrm{Cu}^{2+}$-форму. Для этого через слой ионообменной смолы КУ-2-8 в $\mathrm{Na}^{+}$-форме, помещенной в виде однородной смеси с дистиллированной водой в вертикальную стеклянную колонку диаметром 20-25 мм, длиной 300-350 мм, снабженную внизу краном, пропускали 2 М водный раствор сульфата меди (II). Затем через слой подготовленного катионита пропускали раствор 0,5 г, очищенной путем диализа натриевой соли сульфатированной МКЦ (содержание серы 12,4\% масс.) в 12,5 мл дистиллированной воды. После прохождения через колонку 12,5 мл раствора соли сульфатированной МКЦ смолу в колонке промывали дистиллированной водой (3 раза по 12,5 мл). Собирали промывные жидкости и упаривали раствор на ротационном испарителе до 5-10 мл при температуре перегонки не более $50^{\circ} \mathrm{C}$. Из полученного в результате отгонки остатка, Сu-СМКЦ выделяли путем высаживания в 100 мл этанола. Образовавшийся осадок - Cu-СМКЦ отфильтровывали, промывали на фильтре 15-25 этанола, высушивали под вакуумом. Сu-СМКЦ хранили для дальнейшего использования в вакуум-эксикаторе при температуре не $>5{ }^{\circ} \mathrm{C}$.

Левданский Владимир Александрович - главный научный сотрудник, доктор химических наук, доцент, тел. (391) 249-55-84, e-mail: vlevdanskij@mail.ru Сквориова Галина Павловна - научный сотрудник, тел. (391) 205-19-42, e-mail: galina.skv@bk.ru Кузнецов Борис Николаевич - заведующий лабораторией, доктор химических наук, профессор, Институт химии и химической технологии СО РАН, заведующий кафедрой, Сибирский федеральный университет, тел. (391) 249-48-94, e-mail: bnk@icct.ru Djakovitch Laurent - Directeur de Recherches, e-mail: laurent.djakovitch@ircelyon.univ-lyon1.fr Pinel Catherine - Directrice, e-mail: catherine.pinel@ircelyon.univ-lyon1.fr
Содержание меди в Сu-СМКЦ определяли методом комплексонометрического титрования ЭДТА с индикатором мурексид [14], остаточный натрий - рентгеноспектральным анализом на растровом электронном микроскопе TM-1000 Hitachi (Япония) с ренгеноспектральным анализатором Swift ED-TM EDX.

ИК-спектры МКЦ и продуктов ее сульфатирования сняты с использованием ИК-Фурье спектрометра Tensor-27 (Bruker, Германия) в области длин волн 400-4000 см ${ }^{-1}$. Обработка спек- 
тральной информации проведена по программе OPUS (версия 5.0). Твердые образцы для анализа готовили в виде таблеток в матрице $\mathrm{KBr}$ (2 мг образца / 1000 мг KBr).

Рентгенофазовый анализ проведен на рентгеновском дифрактометре ДРОН-3 с использованием Сu $\mathrm{K} \alpha$ монохроматизированного излучения ( $\lambda=0,154 \mathrm{нm})$, напряжение $\mathrm{U} 30 \mathrm{\kappa B}$, сила тока 25 мА. Шаг сканирования 0,02 град., время накопления в точке 1 сек. Съемку проводили в интервале брэгговских углов $2 \Theta$ от 5,00 до 70,00 град.

Прозрачные пленки Сu-СМКЦ для исследования методом АСМ получали испарением 6-7\%-ных водных растворов на гладкой стеклянной подложке.

Исследования пленок Сu-СМКЦ методом АСМ в полуконтактной моде проводились с использованием мультимодового сканирующего зондового микроскопа Solver P47 (HT-МДТ, Москва), оснащенным 14 мкм сканером (сканирование образцом) и юстировочным столиком (модель SKM). Сканирование образцов осуществлялось на воздухе при комнатной температуре. В работе использовались кремневые прямоугольные кантилеверы NSG30 (НT-МДТ, Москва) с типичной резонансной частотой колебаний около 330 кГц и константой жёсткости $\approx 40 \mathrm{H} /$ м; длина балки составляла 125 мкм, радиус кривизны иглы был менее 10 нм. Сканирование производилось не менее чем в 3-4 точках на нескольких площадках. Скорость сканирования составляла 1,5-2 Гц, разрешение получаемого изображения $-256 \times 256$ точек. Как правило, сглаживания или иной обработки изображений, за исключением вычета поверхности второго порядка, не проводилось. Шероховатость поверхности рассчитывали по профилю поперечного сечения с использованием программного пакета Nova 926 в соответствии с ГОСТ 2789-73 [15].

Спектры ЭПР регистрировали на ЭПР Фурье-спектрометре BRUKER ELEXSYS E580 в режиме CW при комнатной температуре. Мощность СВЧ $-0,2$ мВт, величина модуляции - 1 Гc (Gs). Моделирование спектров проводили с помощью программ X Sophe, взаимное вычитание спектров проводили с помощью встроенных программ.

\section{Результаты и обсуждение}

Соли сульфатов целлюлозы с различными катионами щелочных и щелочноземельных металлов получают обычно непосредственной нейтрализацией кислотной формы сульфата целлюлозы соответствующими щелочами после ее получения или путем реакции обмена с солями [16]. Получение солей слабых оснований таким путем невозможно. Поскольку натриевая соль сульфатированной МКЦ является полианионом, способным к ионному обмену с катионами металлов, то для введения катионов $\mathrm{Cu}^{2+}$ в молекулу сульфата МКЦ нами было предложено использовать метод ионного обмена.

Для получения Сu-СМКЦ методом ионного обмена применяли катионит КУ-2-8 в $\mathrm{Cu}^{2+}$-форме. Для этого катионит КУ-2-8, выпускаемый в промышленности в Na-форме, переводили в $\mathrm{Cu}$-форму

$$
\mathrm{R}-\mathrm{SO}_{3} \mathrm{Na}+\mathrm{Cu}^{2+} / 2 \rightarrow \mathrm{R}-\mathrm{SO}_{3}\left(\mathrm{Cu}^{2+}\right)+\mathrm{Na}^{+},
$$

где R - матрица смолы КУ-2-8.

Затем осуществляли ионный обмен катионов $\mathrm{Na}^{+}$в сульфатированной МКЦ на ионы меди $\mathrm{Cu}^{2+}$

$$
\text { MKЦ-OSO }{ }_{3} \mathrm{Na}+\mathrm{R}-\mathrm{SO}_{3}\left(\mathrm{Cu}^{2+} / 2\right) \rightarrow \text { MKЦ-OSO }\left(\mathrm{Cu}^{2+} / 2\right)+\mathrm{R}-\mathrm{SO}_{3} \mathrm{Na} .
$$

Ионный обмен проводили в динамическом режиме, при соотношении содержания обменных ионов в КУ-2-8 к содержанию групп $\mathrm{Na}^{+}$равном 60 $\div 70: 1$ (мг/экв: мг/экв).

Полученные медьсодержащие полимеры сульфатированной микрокристаллической целлюлозы представляли собой хорошо растворимые в воде порошки или пленки, окрашенные в сине-зеленый цвет неорганических солей $\mathrm{Cu}^{2+}$.

Полноту ионного обмена определяли по содержанию остаточного натрия в полученных $\mathrm{Cu}-\mathrm{CMKЦ.}$ По данным рентгеноспектрального анализа натрий в образцах Сu-СМКЦ отсутствует, поэтому можно сделать вывод, что обмен натрия на медь протекает полностью. Содержание меди в полученных Сu-СМКЦ было определенно с использованием метода комплексонометрического титрования и составило $12,6-14,1 \%$.

Структура исходной МКЦ и ее сульфатированных производных исследована методом ИКспектроскопии (рис. 1). 
В ИК-спектрах образцов натриевой соли сульфата МКЦ и Сu-СМКЦ присутствуют полосы поглощения в области $800 \mathrm{~cm}^{-1}$ (SO) и $1200 \mathrm{~cm}^{-1}\left(\mathrm{SO}_{2}\right)$, которые подтверждают введение сульфатной группы в структуру целлюлозы. В ИК-спектре Сu-СМКЦ в отличие от ИК-спектра натриевой соли сульфата МКЦ наблюдается расширение и расщепление полосы поглощения сульфатной группы в области $1200 \mathrm{~cm}^{-1}$, соответствующей валентным колебаниям $v_{\text {as }}(\mathrm{O}=\mathrm{S}=\mathrm{O})$, возможно связанное с различным характером внутримолекулярного и межмолекулярного взаимодействия ионов меди с сульфатными группами и гидроксильными группами. Также в ИК-спектре Сu-СМКЦ происходит увеличение интенсивности полосы поглощения в области $1638 \mathrm{~cm}^{-1}$, характерное для деформационных колебаний $\delta(\mathrm{H}-\mathrm{O}-\mathrm{H})$ молекул адсорбированной воды. Это, скорее всего, связано с большей степенью гидратированности медьсодержащего сульфата МКЦ, что определяется способностью ионов меди (II) образовывать аквакомплексы.

Рентгенограммы $\mathrm{Cu}-\mathrm{CMKЦ} \mathrm{показали} \mathrm{его} \mathrm{аморфное} \mathrm{строение} \mathrm{(рис.} \mathrm{2).} \mathrm{На} \mathrm{рентгенограммах} \mathrm{натрие-}$ вой соли сульфата МКЦ и медьсодержащего сульфата МКЦ по сравнению с рентгенограммой исходной МКЦ отсутствует максимум распределения в области $2 \Theta=22$, характерный для МКЦ [17].

Характерной особенностью сигналов от катионов $\mathrm{Cu}^{2+}$ в спектрах ЭПР является наличие значительной анизотропии g-тензора и констант сверхтонкой структуры (СТС) [18]. Однако в спектре ЭПР (рис. 3) образца медьсодержащего сульфата микрокристаллической целлюлозы сигнал от катионов меди представлен в виде слегка ассиметричной линии ( $\left.\mathrm{g}_{0}=2.186, \Delta \mathrm{H}=185 \mathrm{Gs}\right)$, что свидетельствует об отсутствии анизотропии g-фактора и заметных величин значений констант СТС.

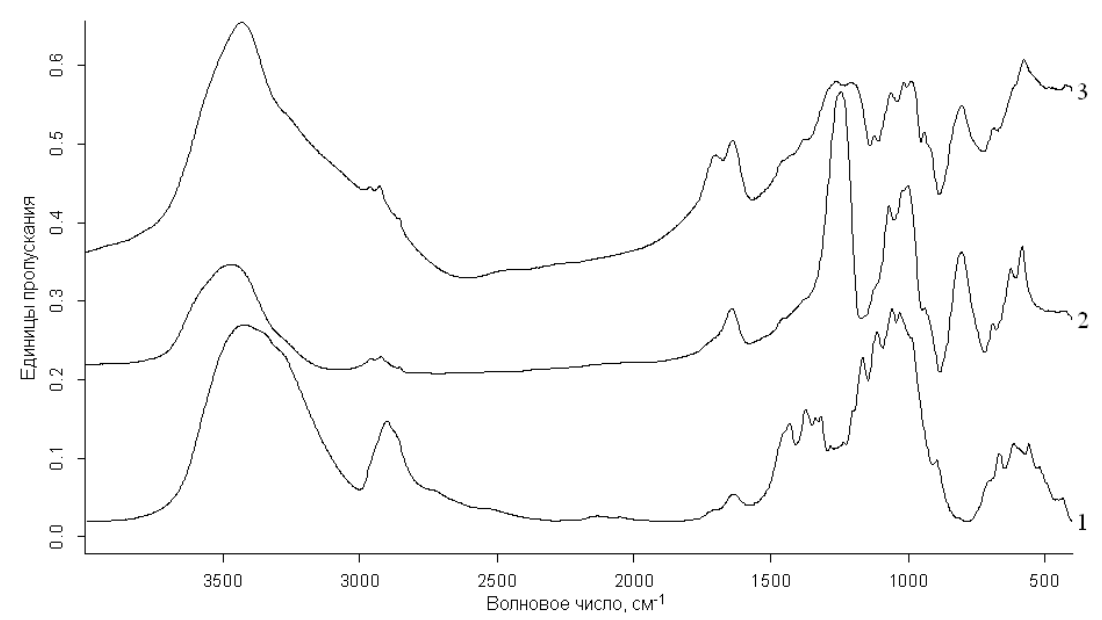

Рис. 1. ИК-спектры образцов: исходной МКЦ (1), натриевой соли сульфата МКЦ (2) и медьсодержащего сульфата МКЦ (содержание меди 13,2 \% масс.) (3)

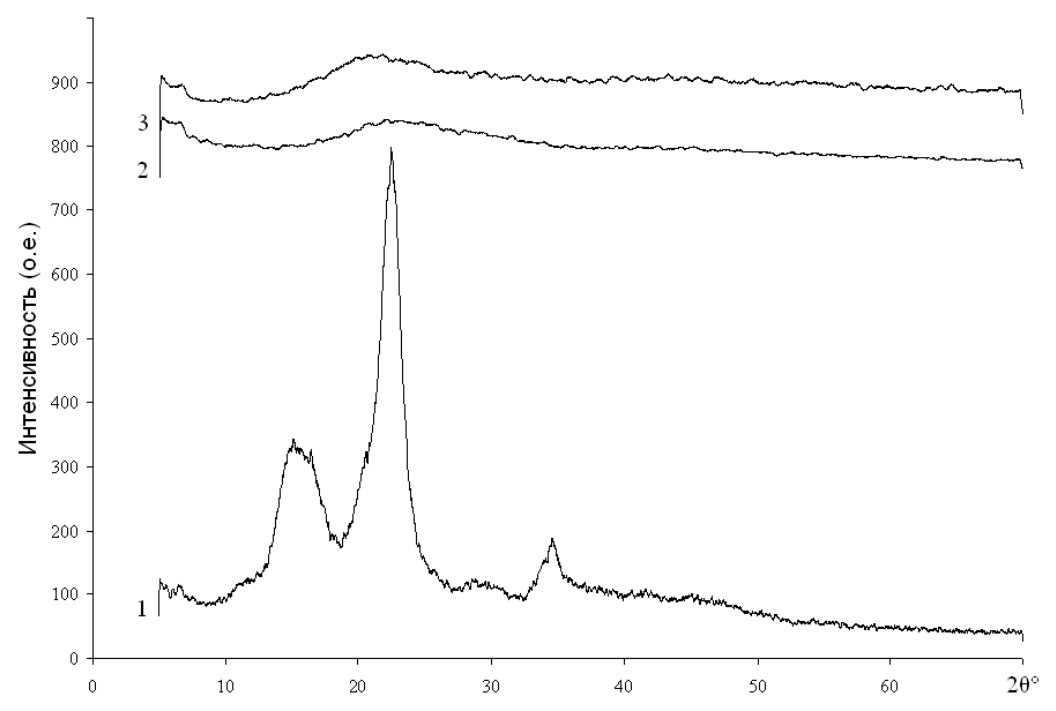

Рис. 2. Рентгенограммы образцов: исходной МКЦ (1), натриевой соли сульфата МКЦ (2) и медьсодержащего сульфата МКЦ (содержание меди 13,2% масс.) (3) 
Отсутствие констант СТС наблюдается в спектрах ЭПР различных солей $\mathrm{Cu}$ (II) и обусловлено наличием обменных взаимодействий между катионами меди. При этом сохраняется анизотропия g-фактора, что связано с ориентационным упорядочиванием мест локализации парамагнитных катионов в кристаллах солей. Поэтому отсутствие анизотропии g-фактора в спектре ЭПР образца Сu-СМКЦ (рис. 3) определяется наличием катионов $\mathrm{Cu}^{2+}$, имеющих различные ориентации осей g-тензоров и связанных между собой обменными взаимодействиями. Таким образом, в образце Сu-СМКЦ наблюдается образование медьсодержащей солевой системы, имеющей псевдокристаллическое строение. Значение $\mathrm{g}_{0}=2.186$ близко к средним значением g-фактора для солей Сu (II), в которых ближайшую координационную сферу катионов меди составляют атомы кислорода (например, для $\mathrm{CuSO}_{4} \cdot 5 \mathrm{H}_{2} \mathrm{O}$ ).

Образцы Сu-СМКЦ, выделенные в виде пленок, были исследованы с помощью метода АСМ в полуконтактной моде (рис. 4).

Рис. 3. Спектр ЭПР образца медьсодержащего сульфата микрокристаллической целлюлозы (содержание меди 13,2\% масс.)

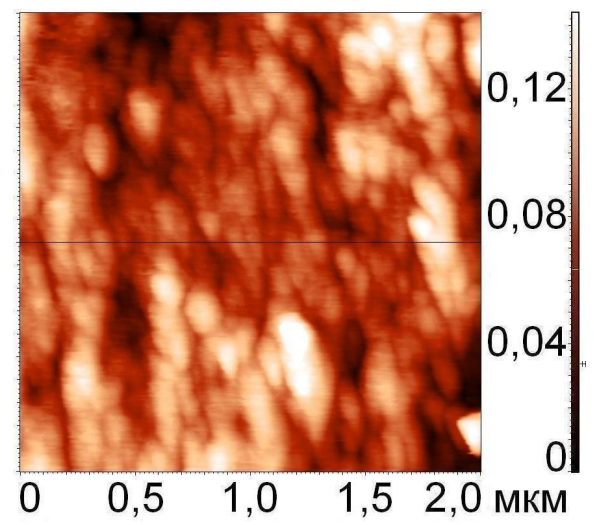

$a$

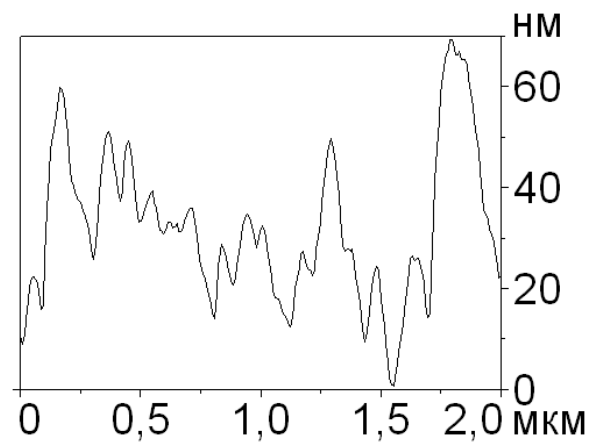

B
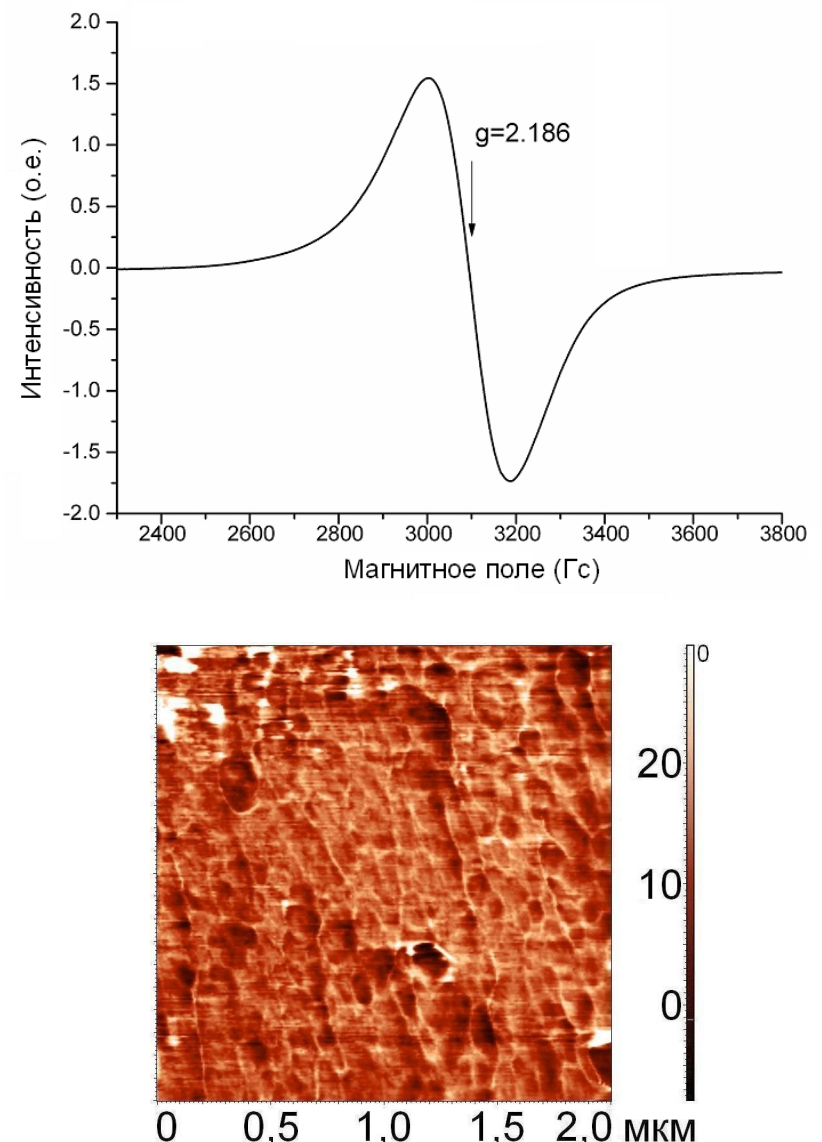

$\sigma$

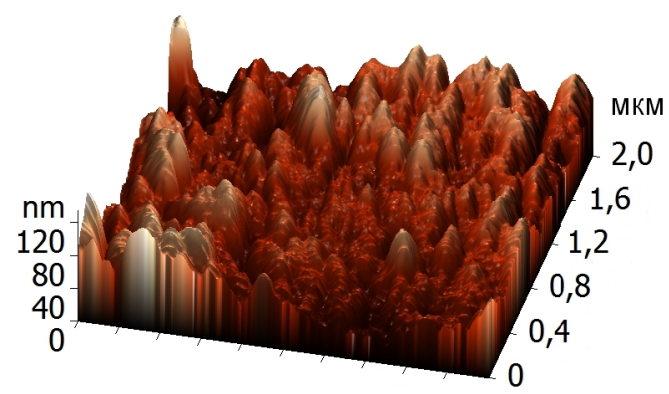

2

Рис. 4. Типичное АСМ изображение пленки медьсодержащего сульфата МКЦ (содержание меди 13,2\% масс.) ( $a$ - рельеф, $\sigma$ - фазовый контраст, в - профиль поперечного сечения вдоль линии на изображении $a, z-$ рельеф в $3 \mathrm{D}$ представлении) 
Как следует из рисунка 4а, поверхность Сu-СМКЦ состоит из достаточно однородных частиц, имеющих сферическую или слегка вытянутую форму и диаметр порядка 70 нм. Величина среднеквадратичной шероховатости, рассчитанная по профилю поперечного сечения поверхности (рис. 4в), составила 32 нм. Поверхность пленки Сu-СМКЦ, согласно изображениям фазового контраста (рис. 4б), достаточно однородна по своему фазовому составу и не содержит инородных включений.

\section{Заключение}

Показана возможность использования метода ионного обмена для получения медьсодержащих полимеров на основе сульфатов микрокристаллической целлюлозы, изучен их состав и строение. По данным химического анализа, содержание меди в полученных образцах составило 12,6-14,1\%.

Методом ЭПР-спектроскопии показано, что образцы Сu-СМКЦ представляют собой медьсодержащую солевую систему, имеющую псевдокристаллическое строение.

По данным АСМ, поверхность пленки Сu-СМКЦ состоит из однородных частиц, имеющих сферическую или слегка вытянутую форму и диаметр порядка 70 нм. По своему фазовому составу поверхность пленки достаточно однородна и не содержит посторонних примесей.

Водорастворимые медьсодержащие полимеры на основе сульфатов микрокристаллической целлюлозы могут найти применение при создании новых лекарственных средств.

\section{Список литературы}

1. Reis R.L., Neves N.M., Mano J.F., Gomes M.E., Marques A.P., Azevedo H.S. Natural-based polymers for biomedical applications. Cambridge: Woodhead Publishing Limited, 2008. 832 p.

2. Varshosaz J. Dextran conjugates in drug delivery // Expert Opin. Drug Deliv. 2012. Vol. 9, N5. Pp. 509-523.

3. Santander-Ortega M.J., Stauner T., Loretz B., Ortega-Vinuesa J.L., Bastos-González D., Wenz G., Schaefer U.F., Lehr C.M. Nanoparticles made from novel starch derivatives for transdermal drug delivery // J. Control. Release. 2010. Vol. 141, N1. Pp. 85-92.

4. Edgar K.J. Cellulose esters in drug delivery // Cellulose. 2007. Vol. 14, N1. Pp. 49-64.

5. Сибикина О.В., Иозеп А.А., Москвин А.В. Комплексы полисахаридов с катионами металлов: применение и строение (обзор) // Хим.-фарм. журн. 2009. Т. 43, № 6. С. 35-39.

6. Авцын А.П., Жаворонков А.А., Риш М.А., Строчкова Л.С. Микроэлементы человека (этиология, классификация, органопатология). М., 1991. 496 с.

7. Son W., Youk J.H., Park W.H. Antimicrobial cellulose acetate nanofibers containing silver nanoparticles // Carbohydr. Polym. 2006. Vol. 65, N4. Pp. 430-434.

8. Nadagouda M.N, Varma R.S. Synthesis of thermally stable carboxymethyl cellulose/metal biodegradable nanocomposites for potential biological applications // Biomacromolecules. 2007. Vol. 8, N9. Pp. 2762-2767.

9. Патент 2203995 (РФ). Способ получения микрокристаллической целлюлозы / В.Г. Данилов, О.В. Яценкова, С.А. Кузнецова, Б.Н. Кузнецов. 10.05.2003.

10. Оболенская А.В., Ельницкая 3.П., Леонович А.А. Лабораторные работы по химии древесины и целлюлозы: учебное пособие для вузов. М., 1991. 320 с.

11. Байклз Н., Сегал Л. Целлюлоза и ее производные. М., 1974. Т. 1. 500 с.

12. Левданский В.А., Левданский А.В., Кузнецов Б.Н. Сульфатирование микрокристаллической целлюлозы хлорсульфоновой кислотой в диоксане // Химия растительного сырья. 2012. №1. С. 39-44.

13. Zagorodni A.A. Ion Exchange Materials: Properties and Applications. Amsterdam: Elsevier, 2006. 456 p.

14. Подчайнова В.Н., Симонова Л.Н. Аналитическая химия элементов. Медь. М., 1990, 279 с.

15. ГОСТ 2789-73 (Рекомендация ИСО Р 486) Шероховатость поверхности. Параметры и характеристики. М., 2006. 7 c.

16. Левданский В.А., Казаченко А.С., Левданский А.В., Кузнецов Б.Н. Изучение сульфатов микрокристаллической целлюлозы, полученных с использованием хлорсульфоновой и сульфаминовой кислот // Журнал СФУ. Химия. 2016. Т. 9, №1. С. 119-133.

17. Ardizzone S., Dioguardi F.S., Mussini T., Mussini P.R., Rondinini S., Vercelli B., Vertova A. Microcrystalline cellulose powders: structure, surface features and water sorption capability // Cellulose. 1999. Vol. 6, N1. Pp. 57-69.

18. Альтшулер С.А., Козырев Б.М. Электронный парамагнитный резонанс соединений элементов промежуточных групп. М., 1972. 670 с.

Поступило в редакичию 14 февраля 2017 г. 
Levdansky A.V. ${ }^{l}$, Vasilyeva N.Yu. ${ }^{1,2}$, Maximov N.G. ${ }^{l}$, Karacharov A.A. ${ }^{l}$, Levdansky V.A. ${ }^{l}$, Skvortsova G.P. ${ }^{l}$, Kuznetsov B.N..$^{1,2}$, Djakovitch L. ${ }^{3}$, Pinel L. ${ }^{3}$ SYNTHESIS AND STUDY OF COPPER-CONTAINING POLYMERS OF MICROCRYSTALLINE CELLULOSE SULFATES FROM LARCH WOOD

\author{
${ }^{I}$ Institute of Chemistry and Chemical Technology SB RAS, FRC KSC SB RAS, Akademgorodok, 50-24, Krasnoyarsk \\ 660036 (Russia),e-mail: inm@icct.ru \\ ${ }^{2}$ Siberian Federal University, pr. Svobodny, 79, Krasnoyarsk, 660041 (Russia) \\ ${ }^{3}$ IRCELYON, 2 avenue Albert Einstein, F-69626 Villeurbanne Cedex, Lyon, (France)
}

For the first time, the synthesis of water-soluble copper-containing sulfates of microcrystalline cellulose (Cu-MCS) was carried out by ion exchange method. The composition of the obtained products was studied using chemical methods and X-ray spectral microanalysis. The copper content in the obtained Cu-MCS samples was $12.6-14.1 \%$. The absence of sodium in the obtained polymer shows complete substitution of sodium cations on the copper cations in the sodium salt of MCC sulfate. The structure of the copper-containing sulfates of microcrystalline cellulose was studied by methods of X-ray diffraction (XRD), Fourier transform infrared spectroscopy (FTIR) and electron paramagnetic resonance (EPR). It was shown by XRD, that CuMCS and the sodium salt of MCC sulfate had amorphous structure in contrast to the samples of the original MCC, with a high degree of crystallinity. According to EPR data there is a formation of copper-containing salt system with a pseudo-crystalline structure in the samples of Cu-MCS. As shown by atomic-force microscopy, the surface of the Cu-MCS films consists of homogeneous crystallites which have a spherical or slightly extended form and the sizes of about $70 \mathrm{~nm}$. The film surface was quite homogeneous in its phase composition and contained no impurities.

Keywords: cellulose sulfate, ion exchange, copper-containing polymers, microcrystalline cellulose, composition, structure.

\title{
References
}

1. Reis R.L., Neves N.M., Mano J.F., Gomes M.E., Marques A.P., Azevedo H.S. Natural-based polymers for biomedical applications. Cambridge: Woodhead Publishing Limited, 2008, 832 p.

2. Varshosaz J. Expert Opin. Drug Deliv., 2012, vol. 9, no. 5, pp. 509-523.

3. Santander-Ortega M.J., Stauner T., Loretz B., Ortega-Vinuesa J.L., Bastos-González D., Wenz G., Schaefer U.F., Lehr C.M. J. Control. Release, 2010, vol. 141, no. 1, pp. 85-92.

4. Edgar K.J. Cellulose, 2007, vol. 14, no. 1, pp. 49-64.

5. Sibikina O.V., Iozep A.A., Moskvin A.V. Khimiko-farmatsevticheskii zhurnal, 2009, vol. 43, no. 6, pp. 35-39. (in Russ.).

6. Avtsyn A.P., Zhavoronkov A.A., Rish M.A., Strochkova L.S. Mikroelementy cheloveka (etiologiia, klassifikatsiia, organopatologiia). [Microelements of a person (etiology, classification, organopathology)]. Moscow, 1991, 496 p. (in Russ.).

7. Son W., Youk J.H., Park W.H. Carbohydr. Polym., 2006, vol. 65, no. 4, pp. 430-434.

8. Nadagouda M.N, Varma R.S. Biomacromolecules, 2007, vol. 8, no. 9, pp. 2762-2767.

9. Patent 2203995 (RU). 10.05.2003. (in Russ.).

10. Obolenskaia A.V., El'nitskaia Z.P., Leonovich A.A. Laboratornye raboty po khimii drevesiny $i$ tselliulozy: uchebnoe posobie dlia vuzov. [Laboratory work on wood chemistry and cellulose: a textbook for high schools]. Moscow, 1991, 320 p. (in Russ.).

11. Baiklz N., Segal L. Tselliuloza i ee proizvodnye. [Cellulose and its derivatives]. Moscow, 1974, vol. 1, 500 p. (in Russ.).

12. Levdanskii V.A., Levdanskii A.V., Kuznetsov B.N. Khimiia rastitel'nogo syr'ia, 2012, no. 1, pp. 39-44. (in Russ.).

13. Zagorodni A.A. Ion Exchange Materials: Properties and Applications. Amsterdam: Elsevier, 2006. 456 p.

14. Podchainova V.N., Simonova L.N. Analiticheskaia khimiia elementov. Med'. [Analytical chemistry of elements. Copper]. Moscow, 1990, 279 p. (in Russ.).

15. GOST 2789-73 (Rekomendatsiia ISO R 486) Sherokhovatost' poverkhnosti. Parametry i kharakteristiki. [State Standard 2789-73 (Recommendation ISO R 486) Surface roughness. Parameters and characteristics]. Moscow, 2006, 7 p. (in Russ.).

16. Levdanskii V.A., Kazachenko A.S., Levdanskii A.V., Kuznetsov B.N. Zhurnal SFU. Khimiia, 2016, vol. 9, no. 1, pp. 119-133. (in Russ.).

17. Ardizzone S., Dioguardi F.S., Mussini T., Mussini P.R., Rondinini S., Vercelli B., Vertova A. Cellulose, 1999, vol. 6, no. 1, pp. 57-69.

18. Al'tshuler S.A., Kozyrev B.M. Elektronnyi paramagnitnyi rezonans soedinenii elementov promezhutochnykh grupp. [Electronic paramagnetic resonance of compounds of elements of intermediate groups]. Moscow, 1972, 670 p. (in Russ.).

Received February14, 2017

Revised March 31, 2017 

